NBER WORKING PAPER SERIES

\title{
DEATH SPIRAL OR EUTHANASIA? \\ THE DEMISE OF GENEROUS GROUP HEALTH INSURANCE COVERAGE
}

\author{
Mark V. Pauly \\ Olivia Mitchell \\ Yuhui Zeng \\ Working Paper 10464 \\ http://www.nber.org/papers/w10464
}
NATIONAL BUREAU OF ECONOMIC RESEARCH
1050 Massachusetts Avenue
Cambridge, MA 02138
May 2004

The researchers acknowledge support from the Pension Research Council at the Wharton School and the Department of Health Care Management Systems. Comments from Leny Bader are appreciated. Opinions are solely those of the authors and not of the institutions with which the authors are affiliated. This research is part of the NBER programs on Aging and Labor Economics. The views expressed herein are those of the author(s) and not necessarily those of the National Bureau of Economic Research.

(C2004 by Mark V. Pauly, Olivia Mitchell, and Yuhui Zeng. All rights reserved. Short sections of text, not to exceed two paragraphs, may be quoted without explicit permission provided that full credit, including (C) notice, is given to the source. 
Death Spiral or Euthanasia? The Demise of Generous Group Health Insurance Coverage Mark V. Pauly, Olivia Mitchell, and Yuhui Zeng

NBER Working Paper No. 10464

May 2004

JEL No. I11, G22

\section{ABSTRACT}

Employers must determine which sorts of healthcare insurance plans to offer employees and also set employee premiums for each plan provided. Depending on how they structure the premiums that employees pay across different healthcare insurance plans, plan sponsors alter the incentives to choose one plan over another. If employees know they differ by risk level but premiums do not fully reflect these risk differences, this can give rise to a so-called "death spiral" due to adverse selection. In this paper, we use longitudinal information from a natural experiment in the management of health benefits for a large employer to explore the impact of moving from a fixed dollar contribution policy to a risk-adjusted employer contribution policy. Our results suggest that implementing a significant risk adjustment had no discernable effect on adverse selection against the most generous indemnity insurance policy. This stands in stark contrast to previous studies, which have tended to find large impacts. Further analysis suggests that previous studies which appeared to detect plans in the throes of a death spiral, may instead have been experiencing an inexorable movement away from a non-preferred product, one that would have been inefficient for almost all workers even in the absence of adverse selection.
Mark V. Pauly
Olivia Mitchell
Yuhui Zeng

Department of Health Care Systems Department of Risk and Insurance Department of Health Care Systems The Wharton School The Wharton School The Wharton School The University of Pennsylvania The University of Pennsylvania The University of Pennsylvania Room 208 Colonial Penn Center 3641 Locust Walk 3641 Locust Walk 3641 Locust Walk Philadelphia, PA 19104 Philadelphia, PA 19104

Philadelphia, PA 19104 and NBER and NBER mitchell@wharton.upenn.edu

pauly@wharton.upenn.edu 


\section{Introduction}

Companies often offer employees an opportunity to select a health insurance plan from a number of choices offered to workers in the group benefit setting. Inasmuch as healthcare plans differ in coverage and premiums, plan sponsors must decide how to structure the premiums that employees pay, since those premiums alter the incentives to choose one plan over another. One recommended strategy follows a "fixed dollar contribution" model, in which the employer nominally 'credits' each employee with the same fixed level of (tax-shielded) compensation dollars which can be used toward any plan purchase. Under this model, plan-specific premiums actually paid by employees are set to reflect differences in average total costs across plans (Enthoven, 1980).

If all workers were of approximately the same level of risk, employee choice would (ideally) reflect differences in the value they place on the benefits associated with each plan. Relative to their incremental costs, workers would then efficiently select the plans that give them the highest net benefits. This attractive property may be eroded, however, if workers know that they differ by risk level but premiums charged to employees do not fully reflect these risk differences. This can give rise to adverse selection if (other things equal) a higher risk employee concludes that the relative benefit enhancements expected from a more generous plan exceeds his incremental premium. In such a world, higher-risk employees (and employees with higherrisk families) would be predicted to differentially enroll in more generous healthcare plans.

If employers then set incremental employee premiums for each plan proportionally to the expected incremental claims costs of participants who actually elect that plan, premiums for the more generous plan will be higher than it would have been, had the plan been selected by a representative cross-section of all employees. This higher premium, in turn, may drive low-risk 
enrollees away, resulting in what has come to be known as a "death spiral". Even if an (interior) equilibrium is reached, it will be one in which enrollment in generous plans will be lower than it would have been, had premiums been based on the average risk across all workers. A number of recent studies report that more generous plans have been or could be adversely selected against, and the estimated response magnitudes are quantitatively important (Cutler and Reber, 1998; Cutler and Zeckhauser, 2000; Buchmueller and Feldstein, 1997).

One way to deter such a death spiral might be to set the predetermined employer contribution in a risk-adjusted fashion, which will in turn influence employee premium differentials. The argument is that such risk adjustment might be more equitable and more efficient than permitting the premium differential to reflect equilibrium plan choices and actual average claims expenses. While an industry has emerged to help employers compute such risk adjusted premiums, no economic study has thus far explored how effective such risk-adjustment is, in tempering adverse selection behavior in the group health insurance context. Rather, prior research has typically examined the effects of introduction of "fixed dollar" models in situations in which previously either differentials did not exist, or premium contributions were proportional (Cutler and Reber, 1998; Royalty and Solomon, 1999) .

In this paper we report on a natural experiment in the management of health benefits for a large university employer where two interesting changes were made: (1) a risk-adjusted employer contribution approach was substituted for what had been roughly a fixed-dollar contribution; and then (2) over time, the risk-adjusted contribution approach was held nearly constant. Thus we have the opportunity to observe the initial impact of introducing risk adjustment, and also to evaluate its continuing effects over time. Our results, which may be surprising to some, suggest that implementing a significant risk adjustment had no obvious 
discernable effect on adverse selection against the most generous indemnity insurance policy. This stands in stark contrast to previous studies which suggested that there would be a large impact.

In what follows, we first show that the data on enrollment movements support the "no effect" hypothesis. Next, we provide empirical analysis that seeks to explain why the earlier empirical models may not apply here. Finally, we draw some conclusions about the significance of this experience. The evidence leads us to hypothesize that employee preferences were already shifting away from the generous indemnity plan and toward much less costly managed care plans, even before risk adjustment was introduced. Thus what may have appeared to be the throes of a death spiral might actually have been an inexorable shift away from a non-preferred product, one that would have been inefficient for almost all workers even in the absence of adverse selection. In sum, erosion of market share of a plan chosen by higher risks may not be entirely due to inefficient adverse selection.

\section{The Natural Experiment}

For many years, the employer in question has offered a choice of health insurance options to its approximately 10,000 non-unionized faculty and staff members. A decade ago, the most popular choice was called "Plan 100," a conventional fee-for-service (FFS) plan that (at one time) had a $\$ 100$ deductible for employee-only coverage. This plan was effectively self-insured, with total premiums in a given year dependent on the plan-specific enrollees' claims experience in the previous year. Above a deductible, the plan paid the usual 80 percent of approved outpatient charges, and it gradually had added outpatient, mental health, and prescription drug coverage. The employer also offered HMO coverage from the two largest HMOs in the area: an 
Aetna HMO and a Keystone (BC/BS) Health Plan. ${ }^{1}$ The two HMOs slowly increased their share of employees between the early and mid-1990s; after that point, the market share of Plan 100 went into a steep decline. This decline accelerated in 1995 when the sponsor added "P-Care," a PPO organized around the employer's healthcare system which was heavily patronized by employees. P-Care offered a lower premium than Plan 100, but its-out-of network benefits had cost-sharing levels that were comparable to those of Plan 100, and its employee premium was much lower.

During the early 1990s, the plan sponsor followed an approximately fixed-dollar contribution model for each plan, within employee rating class (single or family coverage). That is, the variation in employee premiums across plans roughly tracked the variation in total expenditures across all plans. As the managed care total premiums fell relative to the Plan 100 premium, employee premiums for managed care plans went to zero or even become slightly negative (which meant more benefit dollars for the person's other cafeteria plan choices). ${ }^{2}$ Table 1 compares the Plan 100 premium with a simple average of the premiums for other plans using both absolute and relative differences.

\section{Table 1 here}

In 1996, a consulting firm recommended to the plan sponsor that employee premiums be restructured to offset actual plan-specific claims experience - in other words, to embody strong risk adjustment. In particular, the analysts estimated what premiums for each plan would have been if the workers who selected each plan had the risk characteristics of the average worker who takes insurance (based only on age, sex, and wage level). These "risk-adjusted" premiums

\footnotetext{
${ }^{1}$ In addition some plans with small enrollments were limited to employees who were residents of particular nearby states and small HMOs that subsequently exited the regional market.

${ }^{2}$ The employee HMO premiums would have been even more negative if the fixed-dollar model had been followed strictly.
} 
were set at levels such that, given the number of workers who actually choose each plan and their risk levels, the expected aggregate cost for the self-insured plans and the expected premiums for the external HMOs would be covered. The University's contribution to this risk adjusted premium was then set at a uniform dollar amount based on the University's target budget for health benefits. The employee contribution then becomes the difference between the University contribution and the risk-adjusted premium.

The rationale offered for this change flowed primarily from non-economic normative arguments underlying risk adjustment in the health insurance arena. Thus, on fairness grounds, some contended that older and sicker employees who elected Plan 100 should not be asked to pay more, even though they would receive higher healthcare benefits on average due to their above-average utilization. It is interesting that in this discussion, little attention was given to the role of healthcare benefits in attracting high quality workers or minimizing labor costs. On efficiency grounds, the lack of risk adjustment could be expected to distort plan choices, particularly among especially risk-averse young workers who might have preferred Plan 100's generous benefits. On equity grounds, there might also have been discussion of the normative issue that Plan 100 members were more highly paid than members of the other plans, especially the HMOs, but this issue was not prominent at the time. ${ }^{3}$

Table 1 indicates how this change in philosophy influenced both absolute and relative premium differentials, if we compare the old and the new pricing philosophies. In practice, the new approach altered individual plan premiums substantially: for example, in 1996-7, the total monthly premium for the HMO-PA plan was $\$ 302$ per month for family coverage, whereas after the change, monthly premiums jumped to $\$ 428$. By contrast, the Plan 100 total monthly premium fell from an unadjusted value of $\$ 521$ to a risk-adjusted value of $\$ 462$. For single 
employees, the Plan 100 premium rose modestly (in percentage terms), while the two HMO premiums went from negative to positive amounts.

The following year (1997-8), a new point-of-service plan (U-POS) was added to the menu of choices offered. This was a point of service gate-keeper HMO linked to the employer's health system as well as a broader HMO network with higher copayments for out-of-network use. Its employee premium was set at half the employee premium for P-Care. Employee contributions were "rounded off" in some cases, and the two HMO employee premiums were set equal to each other since neither the total premiums nor the mix of risks was much different.

Not long thereafter, a new benefits consulting group was engaged which again altered the philosophy for setting employee healthcare plan premiums. Though risk-adjusted employee premiums were not completely discarded, as of 1997-8 some changes in employee premiums began to emerge gradually. Between then and 2000-01, the ratio between Plan 100 premiums and other premiums slowly widened. The two HMO employee premiums remained equal, and the more restrictive POS plan associated with the employer's Health System continued to cost employees half the premiums of the less restrictive P-Care plan. In 2002-3 the plan sponsor froze further enrollment in Plan 100 in view of low membership and boosted the employee premium substantially, with the eventual aim of phasing out this plan.

\section{What Difference Do Employee Premiums Make?}

Figure 1 illustrates employee enrollment data across health plans at this employer, both before and after the introduction of the new premium pricing philosophy in 1997-8. Enrollment percentages in Plan 100 fell steadily over the period, despite the rise in relative Plan 100 premiums up to 1997 and dramatic reductions in relative Plan 100 premiums after that point.

\footnotetext{
${ }^{3}$ Quality of care concerns regarding HMOs that were later raised by researchers were not an issue at that time.
} 
Overall, enrollment data trends offer little support for the view that enrollment patterns were influenced by premium changes.

Figure 1 here

In what follows, we therefore evaluate some more rigorous empirical models to address several relevant questions: (1) Are employees of this firm less responsive to relative premiums than those studied by other researchers? (2) Does employee income matter -- in that income affects both the choice of plan and (because the employer had a cafeteria plan) the net-of-tax employee premiums? Finally, (3) can we distinguish the hypothesis of a gradual shift in demand away from the most generous plan, from a death spiral induced by adverse selection?

\section{Modeling the Problem}

The key puzzle on which we focus is why was there so little reaction to the large decline in relative price for Plan 100, the old-style FFS plan offering. In fact, no one new joined this plan, and there was little slowdown in the rate at which enrolled participants exited over time. What can this teach us about adverse selection and death spirals?

We define an empirical death spiral in a multiple option group insurance setting as a situation in which, over time, a plan disproportionately chosen by higher risks (a) loses membership, and (b) experiences an increasing average level of risk, given the employer's policy for setting employee premium contributions.

Both clauses are important. Clause (a) describes the informal understanding of a death spiral, but it alone does not rule out the possibility that a plan loses membership because, given changes in plan costs for someone of average risk, and given changes in demand, that plan type is becoming less popular (irrespective of the risk levels of those who tend to select it). That is, 
clause (b) indicates that even if the relative premium employees pay did perfectly reflect differences in risk at one point in time, above-average risks might -- over time -- move away from the plan if its costs rose disproportionately or if other plans were introduced that were more attractive. Even these two conditions are only necessary, but not sufficient, for there to be an adverse selection induced death spiral, since it is possible that new options introduced may have appealed more to the lower-risk members of the shrinking plan, even with perfect risk rating. These observations raise an important issue which has thus far been ignored in the literature: what is the benchmark model or the null hypothesis, when testing whether a plan is losing membership because of an adverse-selection death spiral. One attractive benchmark is what would have happened had premiums been perfectly risk-rated; in such a situation, there would be no adverse selection. But previous studies seem to have another, more restrictive benchmark in mind, one in which people were initially distributed across different types of plans independently of risk (Robinson, et al., 1991). This second benchmark is more restrictive, because it ignores the real possibility that it could be efficient for higher risks to be disproportionately in one type of plan rather than another in a perfectly risk-rated world. For example, evidence from the risk-rated individual insurance market suggests that older buyers are less likely to choose HMOs or restrictive PPOs relative to less restrictive indemnity plans.

Traditional modeling in this area has assumed that people do move across plans in response to employee premium differences. Prior analysis has used two different types of dependent variables. One more common approach assumes that the probability that an employee chooses a particular plan in a given time period depends on the difference (measured in various ways) between that plan's employee premium and those of other plans (c.f. Barringer and Mitchell, 1994 who follow Feldman, et al., 1989). Another modeling tactic relates the 
probability of switching out of one's current plan at a given time to the change in the premium difference between that period and a previous one (c.f. Beaulieu, 2002). Below, we show results for both "choice" and "switching" outcomes.

Our empirical evidence is a formal test of the hypothesis that the rate of decline in Plan 100's share was not affected by the dramatic premium change effected in 1997. To undertake this test, we estimated a microeconomic multinomial Logit regression using plan choice data for approximately 65,800 person years over the period 1992-2000. We focus our analysis on in-state employees who selected one of the offered health insurance plans (thus we omit approximately 10 percent of the sample who selected no plan or no in-state plan.) Two dependent variables are analyzed: one takes on a value of one if the person was in Plan 100 and zero if the person was in any other plan; while the other takes on a value of one if the person switched out of Plan 100 between one year and the next, and was zero otherwise.

Explanatory variables of interest include a measure of the tax-exclusion-adjusted difference in premiums between Plan 100 and a simple average of all other premiums in the family/individual category selected. We also include a time trend variable to test for a secular shift in preferences away from Plan 100, and also we include a count of the number of managed care plans offered in the period. There was no significant change in the coverage provisions of healthcare policies offered other than Plan 100, so only that deductible was adjusted to account roughly for inflation. Since employees received different levels of earnings and therefore would fall under different marginal tax rates, workers' healthcare insurance premiums varied over time, across category, and by income.

It is important to develop an accurate empirical definition of the employee's "price" for a healthcare insurance policy. Naturally, it should reflect the employee's cost of choosing Plan 
100 as well as the price of alternatives to Plan 100. Accordingly, we represent the employee price of alternatives by a simple average of the employee premiums for all plans other than Plan 100 for the type of insurance (family or self-only) actually chosen by the employee. As Cutler and Reber (1998) have noted, in a cafeteria plan (such as at this employer), even this premium is paid out of pre-tax dollars, so the net premium differential is multiplied by $(1-\mathrm{m})$, where $\mathrm{m}$ is the employee's marginal tax rate. The price measure we use is therefore the tax-adjusted absolute difference in premiums (DP) between the Plan 100 employee premium and the composite premium for the offered alternatives.

If the probability of choosing Plan 100 were a function of this net differential, we would have variation in premiums across employees related to their tax rate as well as to other causes of variation We assume that the marginal tax rate on the recorded wage income (on an annual basis) is a proxy for the true rate. This means, however, that net price is highly correlated with total earnings, since only the "steps" in the tax structure make correlation less than perfect. Hence it may be difficult to separately estimate premium and wage (income) effects. Alternatively, we could specify the price measure as the proportional change in the cross-plan differential, in which case the marginal tax rate drops out: a $\$ 10$ increase in a $\$ 100$ differential is a 10 percent increase for all workers facing this set of circumstances regardless of the individual worker's marginal tax rate. The tax rate also drops out if we use as a price measure the relative differential (DP/P) or the $\log$ of DP, since the regression relates variations in DP relative to the mean value of DP. Of course these latter price definitions are less correlated with earnings, but there is also less cross-sectional price variability since the differentials are the same for all workers choosing a particular type of plan in a given year. While we have no a priori basis for 
preferring one functional form to another, the income-related measure is very likely to yield better goodness-of-fit than the price measures that do not vary as much.

\section{Empirical Findings}

In the empirical model, the multivariate regression equations we examine take the form (in the levels or changes):

Plan Choice it $=f(D P, t, N$, Tenure, $F, R$, Age, Salary, Interactions $)$,

where control variables besides the price differential and the time trend indicate the worker's age and salary, whether he was a new hire, and the number of years he worked at the firm. In addition his policy type (family or single) was included. Of most importance is an indicator of when the reform was adopted, $\mathrm{R}$, which is also interacted with the premium difference variable. All variables are summarized in Table 2.

\section{Table 2 here}

Regression coefficients are reported in Table 3. Cross-sectional plan choice results appear in panel (a), and cross-time plan switching results in panel (b). With the large sample size (more than 65,800 observations), all regression coefficients are statistically significant at conventional levels. The results indicate that employee premiums did have a negative effect on demand, and this effect was larger in absolute value for new employees and after the reform was implemented; also, it was smaller for family coverage. Of key interest is the time trend, which indicates a long-term and persistent movement away from Plan 100, even after holding constant the premium differential and holding other factors. Furthermore, the interaction term $(\mathrm{RP}=\mathrm{R} x$ DP) indicates that the movement away from the FFS plan became stronger after the 1997-8 
reform: in other words, the absolute value of the price coefficient actually increased between the two time periods. The increase, however, was small in magnitude.

Table 3 here

The evidence thus leads us to conclude that the employees in these plans did respond to premium differentials over time, but that the premium differential favoring of Plan 100 after 1996-7 was offset by a coincident additional shift in demand away from the FFS plan type. The net effect was a continuation of the erosion as the reform occurred, and an even higher rate of loss of market share after the change.

We also investigate the "first difference" behavior embodied in plan switches by continuing employees given changes in relative premium differences. ${ }^{4}$ Results appear in panel (b) of Table 3. The dependent variable here is the (log) odds that an employee drops out of Plan 100 , and the premium measure is specified as the change in DP between periods $t-1$ and $t$. We did not first-difference any of the other variables because they were either constant over time or changed rarely. Results show that the direct effect of changes in the out-of-pocket premium differential is unexpectedly positive but not statistically significant. It is interesting that the interaction variable $\mathrm{R}^{*} \mathrm{DP}$ is highly significant and negative in sign, which signifies that after the 1997 reform, a given Plan 100 premium differential over the other offerings caused more employees to leave Plan 100, than prior to the reform.

\section{Discussion}

To illustrate our estimated price effects more clearly, we convert Logit effects from the plan choice regression in Table 3 a into elasticity terms; the implied elasticity is approximately 0.78. In other words, this firm's employees do not appear to be unusually inert. To compare our 
results to the Cutler-Reber findings, which appear to use the log of DP, we also reestimated the regression using the log of DP. In this framework, our point estimate for the price elasticity is 0.3 , which is well within the Cutler-Reber range of -0.3 to -0.6 . Clearly, the elasticity results suggest that the behavior of this firm's employees is not atypical. The most important influence on Plan 100's share is the time trend; the (log) odds of being in that plan fell by almost 20 percent $(0.17)$ year after year. Perhaps more importantly, this decline proceeded at an accelerated pace in the post-reform period, more than doubling in magnitude.

Naturally, this leads to a key question: what difference did it make to dramatically change premium risk adjustments? One way to answer this question is to forecast what would have happened to the premium difference in the absence of reform, and then to evaluate what the predicted market share might have been. Because there was relatively little change in the relative premium difference after the reform, we focus on estimating the short-run effect.

To determine the effect of the premium reforms per se on enrollment, we need to simulate what would have happened to Plan 100 enrollments in years after the reform, had the premium differential been set at the (higher) level consistent with previous policy. To do this, we assume that the ratio of the Plan 100 premium to the average of other premiums remained at its 1996 value over the next five years. We then use the Logit regression coefficients to predict the Plan 100 market share in each future period, taking account of the direct effect of prices and their interaction with time.

Figure 2 shows the estimated time path of Plan 100 enrollment under this scenario, versus its actual path through time. The simulations show that enrollment in Plan 100 would have been somewhat lower than what was actually experienced, especially immediately after the relative premium increase. However, the Figure shows that the reform delayed the decline in market

\footnotetext{
${ }^{4}$ The model used here is similar to that in Buchmuller and Feldstein (1997) and Strombom, et al. (2002).
} 
share for only a short time. Indeed, by mid-2000, the share would have been virtually the same with or without the reform. The Figure also indicates what would have happened, had tastes not shifted against Plan 100 at about the same time as the reform. This difference is somewhat more durable, but it still converges to a very small fraction after four years.

Figure 2 here

\section{Conclusions}

In a sense, it appears that this employer's efforts to institute a risk-adjusted premium policy for health insurance across all employees suffered from unfortunate timing. This is because efforts to stabilize Plan 100's membership appeared to have been swamped by a shift in tastes adverse to this traditional fee-for-service plan. We cannot formally test whether the timing of the taste shift was precisely coincidental; more generally, we do not have an explanation of why this shift occurred. It could reflect some complex interactions with premium changes at the time of the reform which our differential measures cannot capture. ${ }^{5}$

Another possibility is that the simultaneous introduction of the PPO plan in 1995 could have had an effect above and beyond including its premium in the average premium. It was fairly generous in its indemnity payments for non-network use. Nevertheless, this argument is not persuasive since that plan's market share remained relatively small. Also its introduction would not explain the continued trend against Plan 100 for several years thereafter, until the end of the 1990s, when the POS plan arrived on the scene. While some of the alternative plans were new or nearly so, the two HMOs had been available for years and their provisions (relative to Plan 100's) did not change much. Possibly one could hypothesize that the nominal-copayment 
managed care plans may have looked more appealing, relative to the proportional coinsurance Plan 100, as medical spending rose, but the rate of increase in health insurance spending actually slowed in this period. A moderately plausible conjecture is that there was some kind of positive "demonstration effect": as more workers joined managed care, they may have reassured those left behind in the old-fashioned plan, thereby inducing further switching.

Regardless of the specific explanation, the policy message is important: adjusting premiums to correct for risk selection may well be of second-order importance, compared to other things affecting employee choice of healthcare plans. The demise of a generous plan is not necessarily due to adverse selection, even when that plan has been observed to be selected by higher risk workers. Of course, as prior studies have noted, small differences in premiums may lead to large adverse selection effects in static theoretical models. But in actual empirical settings where much is changing, these effects may be swamped. Even if selection is predicted before the fact, it may be difficult to find afterward. The theoretical models which predict death spirals, after all, hypothesize that a spiral will result from a linked series of increases in the relative premium of the more generous plan. They do not imply that, holding premiums constant, there should be a continuous trend against that more generous plan.

A question remains as to whether substantial efficiency costs remain, as a result of failure to risk adjust employee premiums. It is hard to say, since the relevant "elasticity" here concerns the assignment of individuals to plans, and not inefficient levels of insurance given a plan. At a minimum, the reform generated few gains to low-risk workers who might have preferred the indemnity plan. In the end, if the reform did anything, we conclude that it only slightly delayed the inevitable demise of an outdated benefits design. Adverse selection therefore may not be as

\footnotetext{
${ }^{5}$ For example, whatever happened to the Plan 100 employee premium relative to the average of other premiums, there could have been an especially salient change in the premium relative to one of the options. This is not, in our
} 
important as sometimes theorized, when one seeks to structure well-functioning health insurance markets. 


\section{References}

Barringer, M., Mitchell O.S., 1994. Workers' preferences among company-provided health insurance plans. Industrial and Labor Relations Review 48, 141-152.

Beaulieu, N., 2002. Quality information and consumer health plan choices. Journal of Health Economics 21, 43-54.

Buchmueller, T.C., Feldstein, P.J., 1997. The effect of price on switching among health plans. Journal of Health Economics 16, 231-247.

Cutler, D., Reber, S., 1998. Paying for health insurance: the tradeoff between competition and adverse selection. Quarterly Journal of Economics 113, 433-466.

Cutler, D., Zeckhauser, R. 2000. The anatomy of health insurance, in Culyer, A., Newhouse, J.P. (Eds.), Handbook of Health Economics, Vol. 1A. Elsevier, Amsterdam, pp. 564-629.

Dowd, B., Feldman, R., 1994-5. Premium elasticities of health plan choice. Inquiry 31, 438-444.

Enthoven, A., 1980. Health Plan: The Only Practical Solution to the Soaring Cost of Medical Care. Addison-Wesley Publishing Company, Reading, Mass.

Feldman R., Finch, M., Dowd, B., Cassou, S., 1989. The demand for employment-based health insurance plans. Journal of Human Resources 24, 115-142. 
Robinson, J.C., Luft, H.S., Gardner, L.B., Morrison E.M., 1991. A method for risk-adjusting employer contributions to competing health insurance plans. Inquiry 28, 107-116.

Royalty, A.B., Solomon N., 1999. Health plan choice: price elasticities in a managed competition setting. Journal of Human Resources 34, 1-41.

Strombom, B.A., Buchmueller, T.C., Feldstein, P.J., 2002. Switching costs, price sensitivity, and health plan choice. Journal of Health Economics 21, 89-116. 
Figure 1a:

Enrollment Percentages for All Continuous Employees (Family)

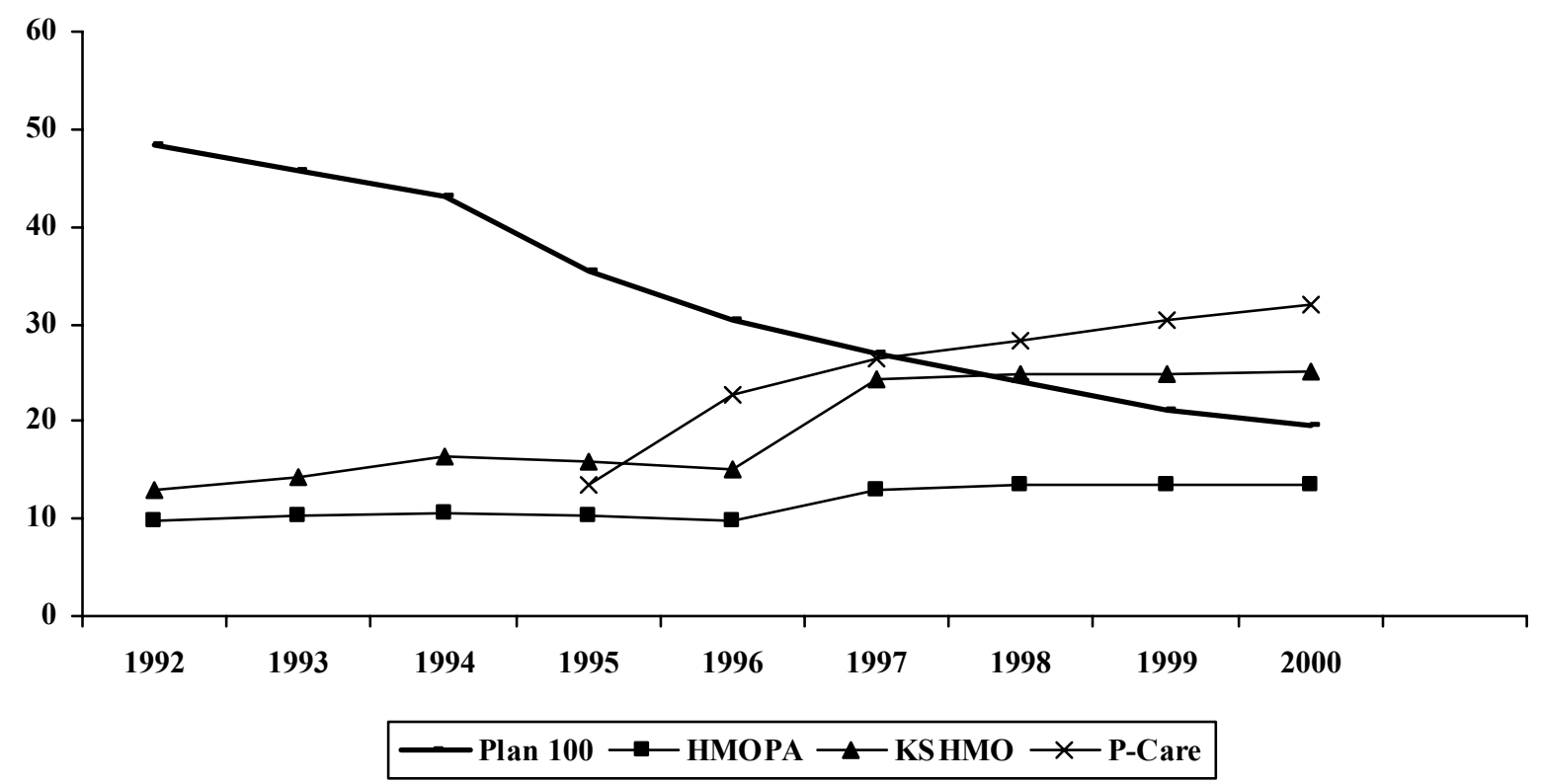

Figure 1b:

Enrollment Percentages for All Continuous Employees (Self-Only)

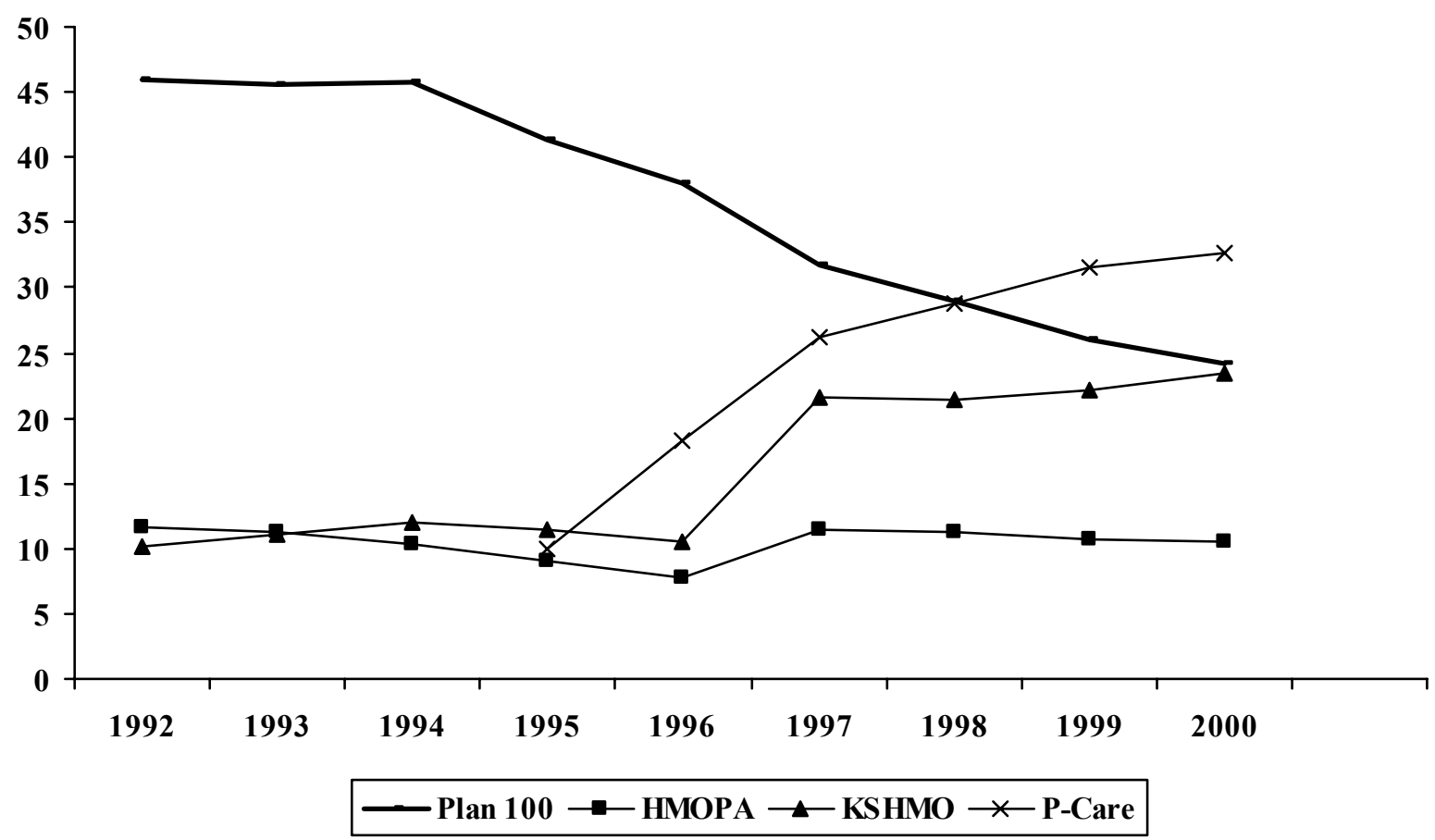


Figure 2: Plan 100 Market Share: Actual vs. Alternative Scenarios

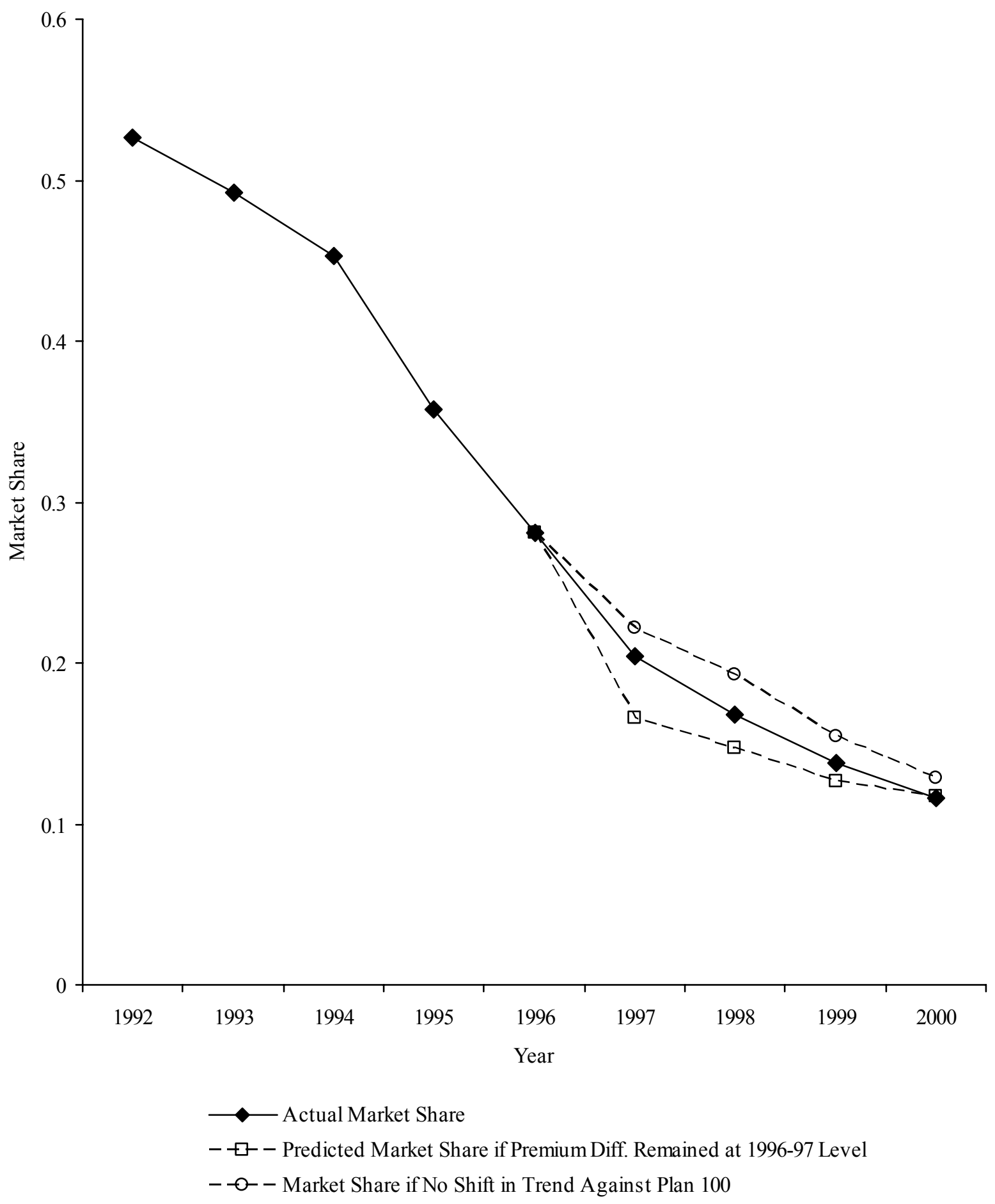


Table 1. Monthly Premium Levels and Differences (\$, 1990-2001).

Self Only

\begin{tabular}{l|ccccccccccc}
\hline & $1990-$ & $1991-$ & $1992-$ & $1993-$ & $1994-$ & $1995-$ & $1996-$ & $1997-$ & $1998-$ & $1999-$ & $2000-$ \\
& 1 & 2 & 3 & 4 & 5 & 6 & 7 & 8 & 9 & 2000 & 1 \\
\hline Plan 100 Premium (\$) & 38 & 44 & 48 & 54 & 58 & 58 & 61 & 66 & 71 & 81 & 94 \\
Average M'ged Care Prem. (\$) & 11 & 16 & 18 & 10 & 1 & -6 & 0 & 20 & 22 & 24 & 27 \\
Difference (\$) & 27 & 28 & 30 & 44 & 57 & 62 & 61 & 46 & 49 & 57 & 67 \\
& & & & & & & & & & & \\
Difference/Plan 100 Premium & 0.71 & 0.63 & 0.63 & 0.81 & 0.98 & 1.07 & 1.00 & 0.70 & 0.69 & 0.70 & 0.71 \\
\hline
\end{tabular}

\section{Family}

\begin{tabular}{l|ccccccccccc}
\hline Plan 100 Premium (\$) & 105 & 119 & 133 & 147 & 159 & 159 & 167 & 172 & 186 & 212 & 244 \\
Average M'ged Care Prem. (\$) & 49 & 46 & 52 & 34 & 20 & 4 & 0 & 52 & 56 & 62 & 70 \\
Difference (\$) & 56 & 73 & 81 & 113 & 139 & 155 & 167 & 120 & 130 & 150 & 174 \\
& & & & & & & & & & & \\
Difference/Plan 100 Premium & 0.53 & 0.61 & 0.60 & 0.77 & 0.87 & 0.97 & 1.00 & 0.70 & 0.70 & 0.71 & 0.71 \\
\hline
\end{tabular}


Table 2: Variables Used in Multivariate Analysis

\begin{tabular}{|c|c|}
\hline Dependent Variable & $\begin{array}{l}\text { Plan Choice: } 1 \text { if Plan 100, } 0 \text { otherwise } \\
\text { Plan Switch: } 1 \text { if switched out of Plan } 100,0 \text { otherwise }\end{array}$ \\
\hline \multicolumn{2}{|l|}{ Explanatory Variables } \\
\hline $\mathrm{DP}_{\mathrm{t}}$ & $\begin{array}{l}\text { Employee Premium Differential: Plan } 100 \text { Premium minus simple } \\
\text { average of all other premiums in period t multiplied by ( } 1- \\
\text { marginal tax rate) in period }\end{array}$ \\
\hline $\mathrm{t}$ & Scalar Time: $1, \ldots, 9$ \\
\hline $\mathrm{F}$ & Family coverage indicator $(0,1)$ \\
\hline $\mathrm{N}$ & New employee indicator $(0,1)$ \\
\hline $\mathrm{R}$ & Reform Indicator: 1 if $1997-98$ or later, 0 else \\
\hline Tenure & Number of years employed with firm \\
\hline FP & Family coverage $*$ Premium Interaction: $\mathrm{F} \times \mathrm{DP}_{\mathrm{t}}$ \\
\hline NP & New employee*Premium Interaction: $\mathrm{N} \times \mathrm{DP}_{\mathrm{t}}$ \\
\hline RP & Reform*Premium Interaction: $\mathrm{R} \times \mathrm{DP}_{\mathrm{t}}$ \\
\hline $\mathrm{Nt}$ & New employee*Time Interaction: $\mathrm{N} \times \mathrm{t}$ \\
\hline Age $30-39$ & Age 30-39 Binary: 1 if in bracket, 0 else ( $<30$ omitted category) \\
\hline Age $40-49$ & Age 40-49 Binary \\
\hline Age $50-59$ & Age 50-59 Binary \\
\hline Age $60+$ & Age $60+$ Binary \\
\hline $\begin{array}{l}\text { Salary between } \$ 50 \mathrm{~K} \\
\text { and } \$ 75 \mathrm{~K}\end{array}$ & Salary binary: 1 if in bracket, 0 else $(<\$ 50 \mathrm{~K}$ omitted category) \\
\hline Salary over $\$ 75 \mathrm{~K}$ & Salary binary: 1 if in bracket, 0 else \\
\hline Sample & All state resident employees choosing a plan \\
\hline
\end{tabular}


Table 3a

Plan Choice Multinomial Logit Regression. Dependent Variable: Choose Plan 100

\begin{tabular}{|c|c|c|}
\hline & Coefficients & $\mathbf{P}>\mathbf{z}$ \\
\hline DP & -0.016 & 0.000 \\
\hline Time & -0.170 & 0.000 \\
\hline Family Coverage & -0.530 & 0.000 \\
\hline New Employee & -0.500 & 0.000 \\
\hline Reform Binary (R) & -0.193 & 0.039 \\
\hline Tenure & 0.038 & 0.000 \\
\hline Interaction: $\mathrm{F} \times \mathrm{DP}_{\mathrm{t}}$ & 0.009 & 0.000 \\
\hline Interaction: $\mathrm{N} \times \mathrm{DP}_{\mathrm{t}}$ & 0.004 & 0.020 \\
\hline Interaction: $\mathrm{N} \times \mathrm{t}$ & -0.344 & 0.000 \\
\hline Interaction: $\mathrm{R} \times \mathrm{DP}_{\mathrm{t}}$ & -0.003 & 0.000 \\
\hline Age 30-39 & 0.034 & 0.000 \\
\hline Age $40-49$ & 1.470 & 0.000 \\
\hline Age 50-59 & 1.863 & 0.000 \\
\hline Age $60+$ & 2.265 & 0.000 \\
\hline Salary $\$ 50-75 \mathrm{~K}$ & 0.297 & 0.000 \\
\hline Salary $>\$ 75 \mathrm{~K}$ & 0.781 & 0.000 \\
\hline Constant & 0.021 & 0.847 \\
\hline
\end{tabular}

Pseudo R ${ }^{2}: 0.2270$

Number of observations: 65815

Prob $\mathrm{Chi}^{2}>0=0.0000$ 
Table 3b

Plan Switching Multinomial Logit Regression. Dependent Variable: Switch Out of Plan 100

\begin{tabular}{|c|c|c|}
\hline & Coefficients & $\mathbf{P}>\mathbf{Z}$ \\
\hline$\Delta \mathrm{DP}$ & 0.005 & 0.625 \\
\hline Time & -0.101 & 0.025 \\
\hline Family Coverage & 0.102 & 0.219 \\
\hline Reform Binary (R) & -1.282 & 0.000 \\
\hline Tenure & -0.014 & 0.000 \\
\hline Interaction: $\mathrm{N} \times \mathrm{DP}_{\mathrm{t}}$ & 1.671 & 0.000 \\
\hline Interaction: $\mathrm{F} \times \mathrm{DP}_{\mathrm{t}}$ & 0.000 & 0.000 \\
\hline Interaction: $\mathrm{R} \times \mathrm{DP}_{\mathrm{t}}$ & -0.018 & 0.000 \\
\hline Age $30-39$ & -0.637 & 0.000 \\
\hline Age $40-49$ & -0.733 & 0.000 \\
\hline Age $50-59$ & -0.961 & 0.000 \\
\hline Age $60+$ & -1.221 & 0.000 \\
\hline Salary $\$ 50-75 \mathrm{~K}$ & 0.064 & 0.494 \\
\hline Salary $>\$ 75 \mathrm{~K}$ & 0.236 & 0.008 \\
\hline Interaction: Age 30-39 DP & -0.009 & 0.386 \\
\hline Interaction: Age 40-49 DP & -0.011 & 0.215 \\
\hline Interaction: Age 50-59DP & -0.006 & 0.481 \\
\hline Interaction: Age $60+$ DP & -0.017 & 0.077 \\
\hline Constant & -5.799 & 0.000 \\
\hline
\end{tabular}

Pseudo $\mathrm{R}^{2}: 0.0699$

Number of observations: 15469

Prob $\mathrm{Chi}^{2}>0=0.0000$ 